\title{
Quality of life and use of health care resources among patients with chronic depression
}

This article was published in the following Dove Press journal:

Patient Related Outcome Measures

26 September 2016

Number of times this article has been viewed

\author{
Renata Villoro' \\ María Merino' \\ Alvaro Hidalgo-Vega ${ }^{2}$ \\ 'Department of Health Economics, \\ Instituto Max Weber, Madrid, \\ ${ }^{2}$ Department of Economics and \\ Finance, University of Castilla-La \\ Mancha, Toledo, Spain
}

Purpose: This study estimates the health-related quality of life and the health care resource utilization of patients diagnosed with chronic depression (CD) in Spain.

Patients and methods: We used the Spanish National Health Survey 2011-2012, a cross-sectional survey representative at the national level, that selects people aged between 18 and 64 years ( $n=14,691)$. We estimated utility indices through the EuroQol five-dimensional descriptive system questionnaire included in the survey. We calculated percentage use of health care resources (medical visits, hospitalizations, emergency services, and drug consumption) and average number of resources used when available. A systematic comparison was made between people diagnosed with CD and other chronic conditions (OCCs). The chi-square test, Mann-Whitney $U$-test, and Kruskal-Wallis test were used to determine the statistical significance of differences between comparison groups. Multivariate analyses (Poisson regression, logistic regression, and linear regression) were also carried out to assess the relationship between quality of life and consumption of health care resources. Results: Approximately, $6.1 \%$ of the subjects aged between 18 and 64 years were diagnosed with CD (average age $48.3 \pm 11$ years, $71.7 \%$ females). After controlling for age, sex, and total number of comorbidities, a diagnosis of CD reduced utility scores by $0.09(P<0.05)$ vs OCCs, and increased the average number of hospitalizations by $15 \%$, the average number of days at hospital by $51 \%$, and the average number of visits to emergency services by $15 \%(P<0.05)$. $\mathrm{CD}$ also increased the average number of visits to secondary care by $14 \%$ and visits to general practitioners by $4 \%$. People with CD had a higher probability of consuming drugs than people with OCCs (odds ratio [OR]: $1.24, P<0.05$ ), but only $38.6 \%$ took antidepressants.

Conclusion: People with CD had significantly lower health-related quality of life than people with OCCs. CD was associated with increased hospital length of stay and involved a higher consumption of emergency services and drugs than OCCs.

Keywords: utility, burden of disease, health care resources, depression, Spain

\section{Introduction}

Depression is a mental disorder affecting over 350 million people throughout the world. It significantly contributes to the morbidity burden and is associated with a considerable reduction in the quality of life and normal functioning of the patients. ${ }^{1}$ The key symptoms of this disease are low mood and loss of interest or pleasure in carrying out usual activities and low self-esteem, with affective, behavioral, cognitive, vegetative, and motor manifestations, all of which have serious repercussions on quality of life and social and occupational fulfillment. ${ }^{2}$ Depression is sometimes accompanied by anxiety, somatic and cognitive symptoms, and impairment of thought processes, and it is one of the most common diseases treated in both primary and secondary care. ${ }^{3}$
Correspondence: Renata Villoro Instituto Max Weber, C/ Norias I23, 2822I Majadahonda, Madrid, Spain Tel +34916362342

Fax +34916346 643

Email Renata.Villoro@imw.es 
According to Sadock and Sadock, depression can be classified as follows: 1) single-episode major depressive disorder (MDD, lasting days or months), 2) recurring MDD (several episodes of major depression), 3) dysthymic disorder or dysthymia (chronic form of depression, less serious than MDD, lasting 2 years), and 4) depressive disorder without further specification. The type of disorder is diagnosed according to the duration and intensity of symptoms. ${ }^{2}$

Previous studies have found that the prevalence of depression in Spain ranges between 3.6\% and 16.6\%, depending on the definition of the disease and the methodology used., ${ }^{4,5}$ It has been shown that patients usually suffer from chronic comorbidities associated with depression, such as digestive problems, neurological disorders, diabetes, or musculoskeletal pain. ${ }^{3,6-9}$

The relationship between depression and health-related quality of life (HRQoL) impairment has been described in the previous literature. In England, Roberts et al found that depression in the general population has a significantly larger impact on health-state utilities than physical health conditions and that utility decrements increase with severity of depression. ${ }^{10}$ In Finland, Saarni et al found that among a wide range of mental illnesses, anxiety, social phobia and depressive disorders, dysthymia, and MDD were associated with the largest losses of HRQoL on the individual level, before and after adjusting for somatic and psychiatric comorbidity. ${ }^{11}$ In France, Sapin et al found that patients with MDD who were not receiving treatment reported a mean EQ-5D utility of 0.33 , with seriously ill patients reporting mean EQ-5D index scores of $0.15 .{ }^{12}$ Depression has also been found to reduce HRQoL in studies carried out in the US, Sweden, and Germany. ${ }^{13-17}$ In Spain, studies assessing the consequences of depression on HRQoL are scarce and are not representative of the whole Spanish population. To the best of our knowledge, only two studies carried out in Catalonia (one of the Autonomous Communities of Spain) address this issue. Sabes-Figuera et al estimated that depression and anxiety together yielded a total loss of 78,742 quality-adjusted life years (QALYs), ${ }^{18}$ while Fernández et al showed that MDD and dysthymia were two of the main diseases responsible for QALY losses among the Catalan primary care patients, slightly below QALY losses due to chronic pain. ${ }^{19}$

As depression is associated with chronic comorbidities that may enhance the burden of the disease and the health care required for their treatment, the impact of depression on patients' health care resource utilization and health care-associated costs has also been studied. In the US, Luber et al found that depressed elderly patients had increased outpatient resource utilization, including frequency of appointments, number of laboratory tests, $\mathrm{X}$-rays and scans, and primary care consultations, and that the association remained significant after controlling for comorbidity. ${ }^{20} \mathrm{Zhu}$ et al found that comorbid depression caused an increase in insurance claims in patients with generalized anxiety disorder and had significant impact on costs. ${ }^{9}$ In Spain, García-Campayo et al found that somatic symptoms associated with MDD were strongly associated with primary care visits and with hospitalizations. ${ }^{21}$ In Catalonia, Salvador-Carulla et al estimated that the total annual cost of depression for 2006 was 735.4 million euros, with $21.2 \%$ corresponding to direct health care costs (including primary care, mental health specialized care, hospitalizations, and pharmacological care). ${ }^{22}$

In Spain, as in other European countries with aging populations and decreasing birth rates, chronic conditions have been officially recognized as a priority target of public health research and health care intervention programs. These should be aimed at decreasing the economic and social impact that chronic conditions may have on society and the public health care systems in the near future. ${ }^{23,24}$ In this context, the burden of chronic conditions that are evident to the general population, such as diabetes, cardiovascular diseases, or cancers, has been relatively studied in Spain, and most prevention programs have targeted these "visible" diseases. ${ }^{25}$ However, due to lack of major physical symptoms, lack of education among the general population, lack of training among primary health care professionals to recognize mental health problems, and also due to a certain degree of stigmatization, the consequences of depression on society have been relatively understudied in Spain. ${ }^{6,19,26,27}$ Understanding the social burden of depression and the way it differs from the burden imposed by other chronic conditions (OCCs) might help highlight the real impact that depression has on society, which in turn might help prioritize resources and shape health care programs to address and prevent depression.

This study was aimed to assess the impact of depression in Spain, focusing on patient self-assessed HRQoL and patient reported utilization of health care resources, including primary and secondary care. It also compares this impact with the burden of OCCs to assess the differential burden of depression within the context of chronicity.

\section{Patients and methods}

We used microdata from the Spanish National Health Survey (SNHS) 2011-2012, a cross-sectional survey representative at the country level, conducted by the Spanish Ministry of Health, Social Services and Equality, and the Spanish 
National Statistics Institute through personal interviews in 21,007 homes. ${ }^{28}$ The SNHS uses a stratified tristage sample: first-stage units are the census sections, second-stage units are the main family dwellings, and in the third stage, one person aged 15 years or above is selected within each household to fill in the adult questionnaire. The questionnaire collects information on health status perception, diagnoses of chronic conditions, limitations in daily life, and consumption of health care resources, including hospital visits, hospitalizations, use of emergency services, and drug consumption. The SNHS uses ratio estimators to estimate the characteristics of the population, implementing reweighting techniques and considering age and sex groups of each Spanish Autonomous Community population. This allows the provision of a weighting factor that can be applied to the sample to extrapolate results to the whole of the Spanish population. The SNHS is available to the public, and its statistical exploitation does not require the approval from an Ethics Review Board. ${ }^{28}$

When collecting information on chronic conditions, the SNHS allows the respondent to select as many conditions as he/she has been diagnosed with from a list of 30 different possible chronic conditions, including the Spanish term "depresión crónica", which literally means "chronic depression" (CD) in English. Unfortunately, the SNHS does not differentiate between different types of $\mathrm{CD}$. This term might therefore include people diagnosed with MDD, dysthymia, or other nonspecified depressive disorders. Thus, our research questions were limited to describing the HRQoL and the use of health care resources among people diagnosed with $\mathrm{CD}$ in general, as included in the SNHS.

We selected people between the age of 18 and 64 years $(n=14,691)$. All individuals who reported being diagnosed with CD were identified. Their health status self-perception, HRQoL, difficulties perceived in everyday life, and use of health care resources were analyzed. The latter included the percentage of patients who were hospitalized, the length of stay in the last hospital admission, the percentage of patients who used emergency services, made visits to health professionals (primary and secondary care physicians), and the percentage of people who consumed any drugs, by therapeutic group. These results were systematically compared with the results obtained for people in the same age group who were diagnosed with one or more of the 30 chronic conditions that are included in the SNHS other than CD, such as "chronic anxiety" (as with $\mathrm{CD}$, this term does not allow differentiating by type of anxiety disorder), chronic back pain, asthma, diabetes, migraine, malignant tumors, urinary incontinence, and high blood pressure among others.
We refer to the population diagnosed with these OCCs as people with OCCs.

HRQoL was estimated in terms of utility indices through the EQ-5D-5L questionnaire (C2015 EuroQol Research Foundation, http://www.euroqol.org/) included in the SNHS 2011-2012. The questionnaire has five dimensions (mobility, self-care, usual activities, pain/discomfort, and anxiety/ depression), each with five possible responses according to their intensity (no problems, slight problems, moderate problems, severe problems, and extreme problems). The EQ5D-5L can therefore record 3,125 different health states. ${ }^{29}$ Each of these states is assigned a utility value using tariffs that are based on population preferences, resulting in an interval between 1 (representing the best imaginable health status) and values below 0 (representing death). We transformed EQ-5D-5L responses into utility indices using previously published valuations of health states for Spain. ${ }^{30}$

Chi-square test, Mann-Whitney $U$-test, and KruskalWallis test were used to determine statistically significant differences between people with CD and OCCs. Results were considered significant if $P$-value was $<0.05$. Multivariate analyses using Poisson regressions, logistic regressions, and linear regressions were also carried out to assess the relationship between quality of life and health care resource consumption. There were no missing values in the data.

The results were extrapolated to the whole of the Spanish population aged between 18 and 64 years using the population-weighting factor provided by the SNHS. All analyses were carried out using the SPSS software, version 22 (SPSS Inc., Chicago, IL, USA).

\section{Results}

The results are presented by the type of parameter analyzed, starting with a description of the prevalence of $\mathrm{CD}$ and its comorbidities compared with $\mathrm{OCC}$, and followed by the impact that CD may have on self-perceived health status, utility level, limitations in daily life, and use of health care resources.

\section{Prevalence and comorbidities}

Overall, 6.1\% of the Spanish population aged between 18 and 64 years were diagnosed with CD (a total of 1,805,151 people in Spain in 2012). The mean age was $48.3 \pm 11$ years and $71.7 \%$ were females. Over half of the people $(54.5 \%)$ belonging to the same age group reported being diagnosed with one or more OCCs (mean age $43.8 \pm 12.1$ years; percentage of females: $51.5 \%$ ). The majority of people with $\mathrm{CD}$ $(65 \%)$ were aged between 45 and 64 years $(50 \%$ of OCCs were observed in this age interval). 


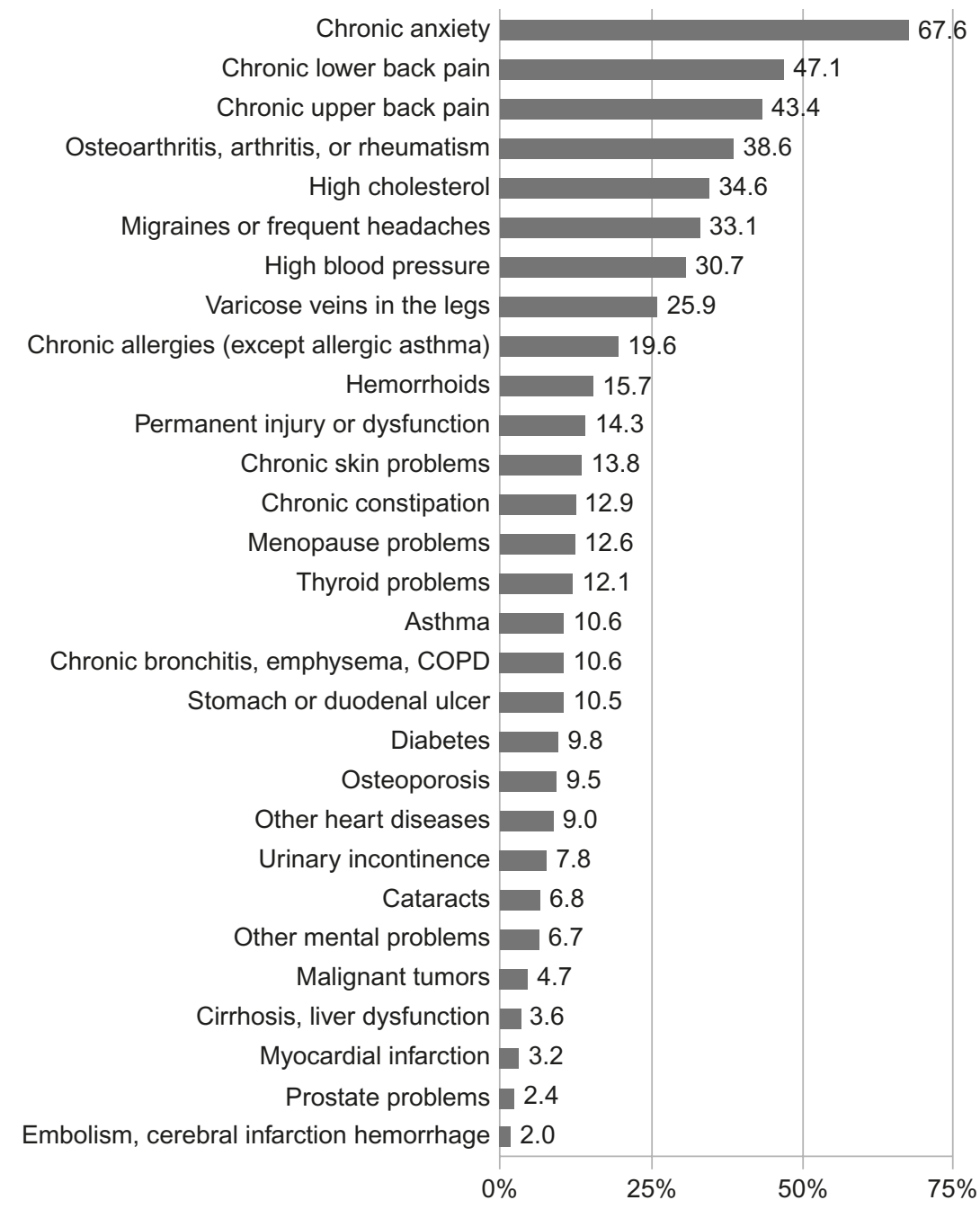

Figure I Comorbidities reported by people with chronic depression. Abbreviation: COPD, chronic obstructive pulmonary disease.

The percentage of patients diagnosed with $\mathrm{CD}$ who reported having additional chronic conditions was $95.3 \%$, with an average of $6.2 \pm 3.4$ chronic conditions per patient, the most frequent of which were chronic anxiety (67.6\%), chronic lower back pain (47.1\%), and chronic upper back pain (43.4\%). In comparison, $58.3 \%$ of patients with OCCs reported having additional chronic conditions, with an average of $2.4 \pm 1.8$ chronic conditions per patient $(P<0.001)$, the most frequent of which were chronic lower back pain (25.7\%), high cholesterol (23.1\%), and high blood pressure (21.9\%). Chronic anxiety (the most common comorbidity among patients with $\mathrm{CD}$ ) affected only $5.8 \%$ of patients with other OCCs (Figure 1).

\section{Self-perception of health status and utility level}

On a five-level health-status grading scale ranging from "very bad" to "very good", $26.9 \%$ of patients with CD perceived

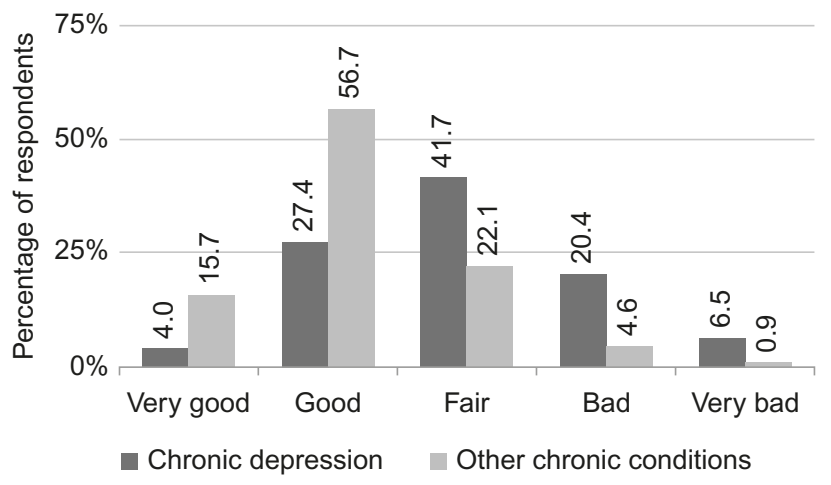

Figure 2 Self-perception of health status among people with chronic depression and with other chronic conditions.

their health status as "bad" or "very bad", while only $5.6 \%$ of patients with OCCs reported the same perception (Figure 2).

Table 1 shows the results of the self-perception of people with $\mathrm{CD}$ and with OCCs on the five HRQoL dimensions included in the EQ-5D-5L questionnaire. In all dimensions, 
Table I EQ-5D-5L dimensions: percentages and results of chi-square test

\begin{tabular}{|c|c|c|c|c|c|}
\hline Dimension & & CD (\%) & OCCs (\%) & Chi-square value & P-value* \\
\hline \multirow[t]{5}{*}{ Mobility } & I have no problems in walking about & 69.9 & 91.8 & 864.770 & $<0.05$ \\
\hline & I have slight problems in walking about & 12.7 & 4.3 & & \\
\hline & I have moderate problems in walking about & 10.4 & 2.6 & & \\
\hline & I have severe problems in walking about & 5.3 & 1.1 & & \\
\hline & I am unable to walk about & 1.6 & 0.3 & & \\
\hline \multirow[t]{5}{*}{ Self-care } & I have no problems washing or dressing myself & 86.7 & 97.5 & 625.620 & $<0.05$ \\
\hline & I have slight problems washing or dressing myself & 4.8 & 1.2 & & \\
\hline & I have moderate problems washing or dressing myself & 5.3 & 0.5 & & \\
\hline & I have severe problems washing or dressing myself & 1.6 & 0.3 & & \\
\hline & I am unable to wash or dress myself & 1.7 & 0.4 & & \\
\hline \multirow[t]{5}{*}{ Usual activities } & I have no problems doing my usual activities & 71.4 & 93.7 & $\mathrm{I}, 094,197$ & $<0.05$ \\
\hline & I have slight problems doing my usual activities & 10.9 & 3.2 & & \\
\hline & I have moderate problems doing my usual activities & 10.8 & 1.9 & & \\
\hline & I have severe problems doing my usual activities & 4.2 & 0.7 & & \\
\hline & I am unable to do my usual activities & 2.8 & 0.5 & & \\
\hline \multirow[t]{5}{*}{ Pain/discomfort } & I have no pain or discomfort & 42.6 & 75.6 & $I,|4|, 76 \mid$ & $<0.05$ \\
\hline & I have slight pain or discomfort & 20.8 & 13.4 & & \\
\hline & I have moderate pain or discomfort & 24.2 & 8.4 & & \\
\hline & I have severe pain or discomfort & 11.0 & 2.4 & & \\
\hline & I have extreme pain or discomfort & 1.4 & 0.2 & & \\
\hline \multirow[t]{5}{*}{ Anxiety/depression } & I am not anxious or depressed & 26.5 & 87.7 & $5,288,372$ & $<0.05$ \\
\hline & I am slightly anxious or depressed & 27.1 & 8.9 & & \\
\hline & I am moderately anxious or depressed & 26.6 & 2.6 & & \\
\hline & I am severely anxious or depressed & 16.5 & 0.6 & & \\
\hline & I am extremely anxious or depressed & 3.3 & 0.2 & & \\
\hline
\end{tabular}

Note: *P-value of chi-square test.

Abbreviations: CD, chronic depression; OCCs, other chronic conditions; EQ-5D-5L, EuroQol five-dimensional descriptive system.

people with CD reported a significantly worse self-perception than those with OCCs $(P<0.05)$. The mental dimension (anxiety/depression) was the most affected among people with $\mathrm{CD} ; 73.5 \%$ reported experiencing anxiety/depression-related problems compared with $12.3 \%$ of patients with OCCs. The most affected dimensions among patients with $\mathrm{CD}$ were pain/ discomfort and problems in doing usual activities (work, study, housework, etc).

The average utility score of patients with $C D$ was $0.74 \pm 0.28$, which was significantly lower $(P<0.001)$ than the average utility score of patients with OCCs $(0.94 \pm 0.14)$.

The results from the linear regression analysis showed that belonging to the CD group (as opposed to the OCC group) implied an average decrease of -0.09 ( $95 \%$ confidence interval $[\mathrm{CI}]-0.10$ to -0.08$)$ points in the utility scores $(P<0.001)$ after controlling for age, sex, and total number of comorbidities (Table 2). An additional comorbidity decreased the utility scores by -0.03 ( $\mathrm{CI}-0.028$ to $-0.025 ; P<0.001)$. There were no statistically significant differences by age and sex, when controlling for total number of comorbidities.

\section{Limitations in daily life}

Ten percent of people diagnosed with CD considered themselves "severely limited" ( $2.4 \%$ of people with OCCs) in everyday activities due to health problems in the past 6 months, as opposed to "not limited" or "moderately limited". Overall, $53.8 \%$ of people with CD reported having physical limitations (vs $92.2 \%$ in OCCs, $P<0.001$ ), $14.8 \%$ reported mental limitations (vs 4\% in OCCs), and $31.4 \%$ had a combination of physical and mental limitations (vs $3.8 \%$ in OCCs) because of a health problem for at least the last 6 months. CD patients were more likely than patients with OCCs to suffer from limitations in carrying out usual activities over the 2 weeks prior to the survey; $31.7 \%$ of people with $\mathrm{CD}$ said they felt their normal activities were limited, compared with $12.1 \%$ of patients with OCCs. One in every five people with CD (19.9\%) stayed in bed at some point during the past 2 weeks (average of $5.0 \pm 4.2$ days), compared with $5.4 \%$ of people with OCCs (average of $4.0 \pm 3.8$ days).

Compared to patients with OCCs, a larger percentage of patients diagnosed with CD reported experiencing mental health-related problems with a "worse than usual" frequency (as opposed to a "better than usual" or "usual" frequency) in the past 2 weeks. Figure 3 compares the percentage of people who reported having worse problems than usual in the different dimensions of mental health included in the SNHS. The most significant problems among people 
Table 2 Utility level and use of health care resources: univariate analysis and results of regression models

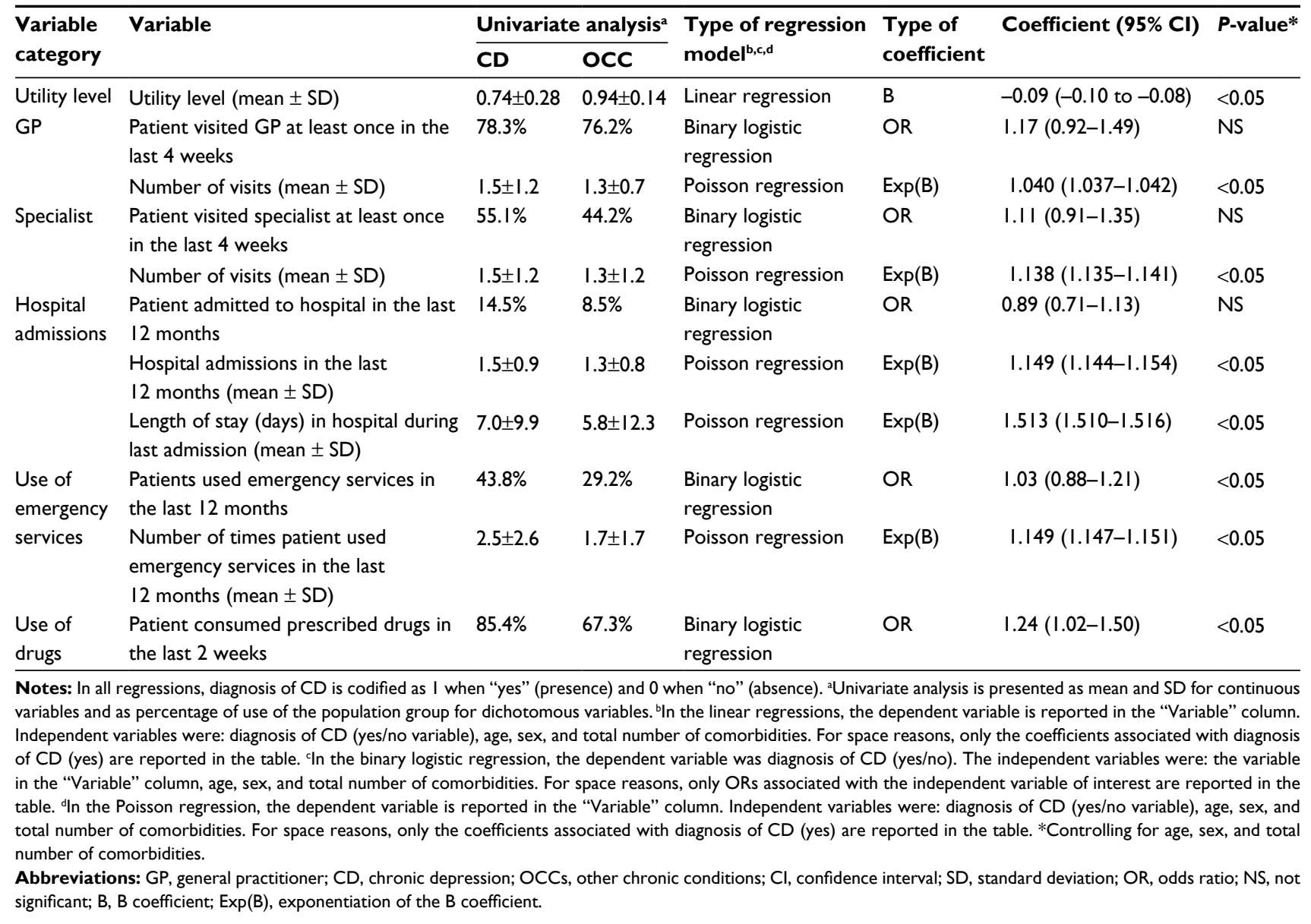

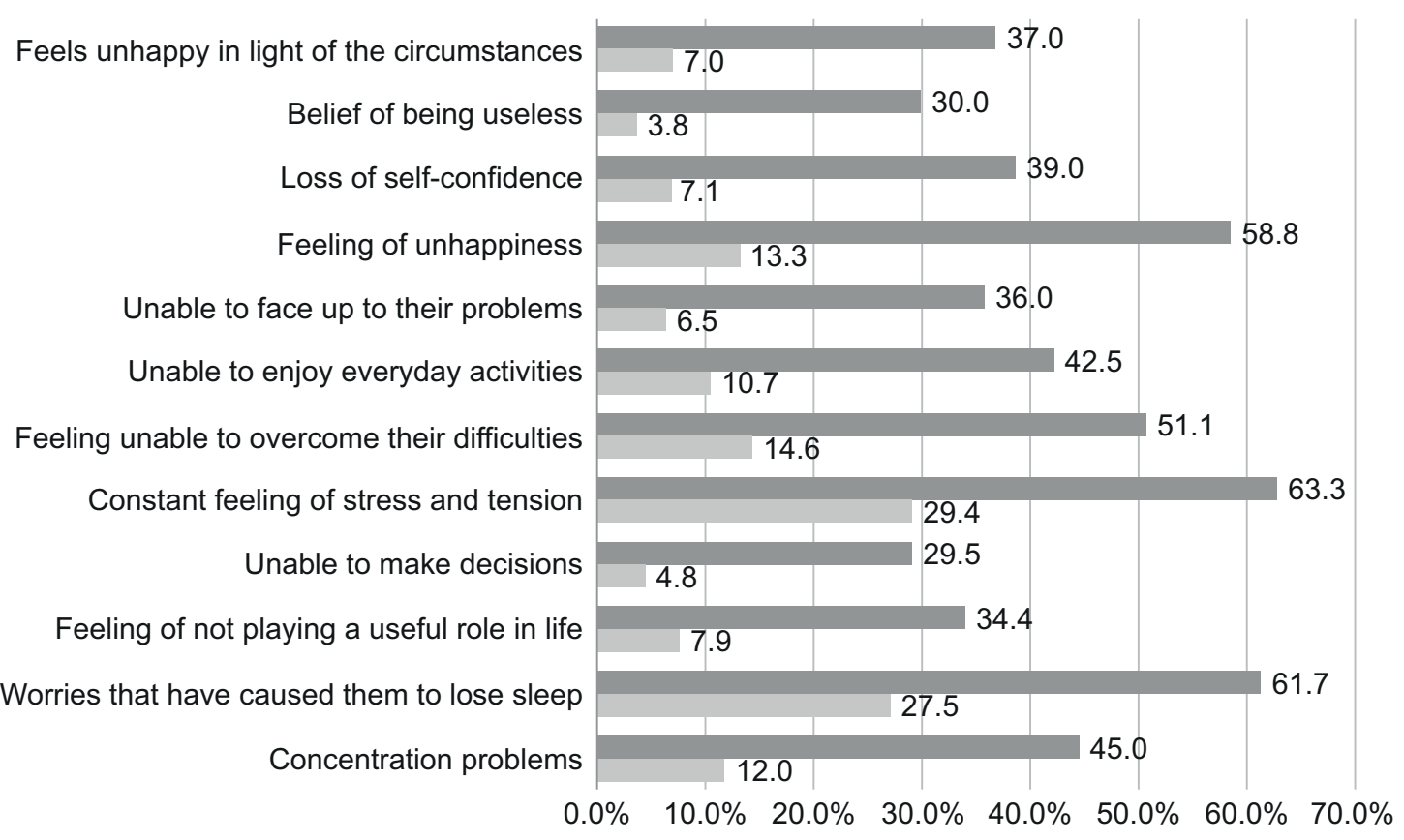

Chronic depression $\quad$ Other chronic conditions

Figure 3 Percentage of people who reported having mental health problems that were worse or much worse than usual in the last 2 weeks. 


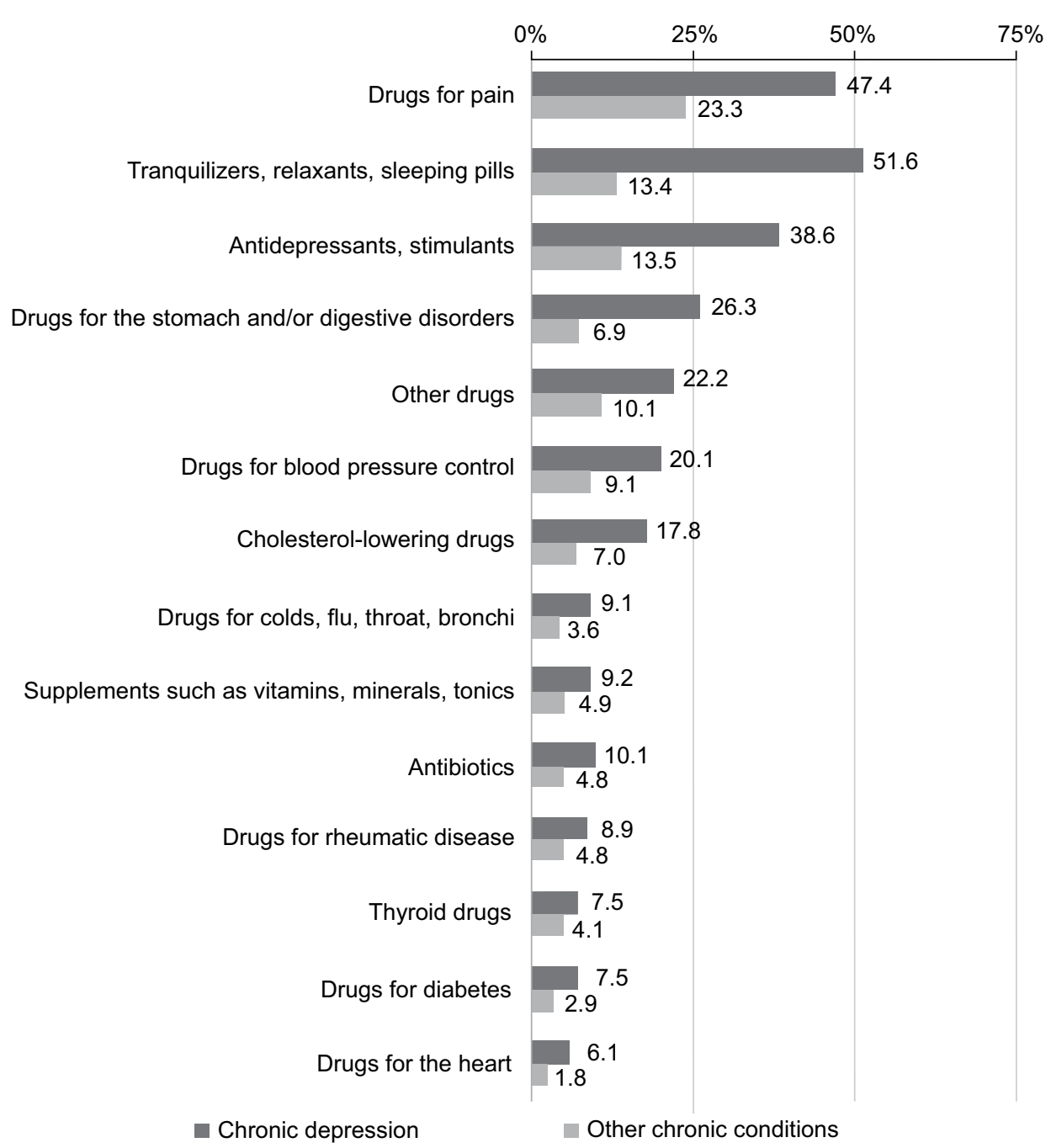

Figure 4 Percentage of patients consuming prescribed medication.

diagnosed with $\mathrm{CD}$ were the "constant feeling of stress and tension" (63.3\% vs $29.4 \%$ in OCCs), "worries that have caused them to lose sleep" (61.7\% vs $27.5 \%$ in OCCs), and "feelings of unhappiness" ( $58.8 \%$ vs $13.3 \%$ in OCCs). The greatest differences between the two populations were "feelings of unhappiness", followed by "feeling unable to overcome their difficulties".

\section{Use of health care resources}

In comparison to patients with OCCs, patients with $\mathrm{CD}$ reported higher rates of visits in the last 4 weeks to primary care physicians $(78.3 \%$ vs $76.2 \%)$ and specialists $(55.1 \%$ vs $44.2 \%)$, hospital admissions in the last 12 months (14.5\% vs $8.5 \%$ ), and use of emergency services in the last 12 months (43.8\% vs 29.2\%) (Table 2). After controlling for age, sex, and total number of comorbidities, patients belonging to the CD group experienced a $15 \%$ higher number of hospitalizations, a 51\% longer hospital length of stay, and 15\% higher number of visits to emergency services in the past year than people diagnosed with OCCs. Visits to general practitioner and specialists were $4 \%$ and $14 \%$ higher, respectively, compared to OCC group. Overall, $85.4 \%$ of patients with CD had taken medication prescribed by a physician in the last 2 weeks (67.3\% for OCCs). After controlling for age, sex, and total number of comorbidities, consumption of drugs was $24 \%$ higher among patients with $C D$ in opposition to patients with OCCs (odds ratio [OR]: 1.24, CI: 1.02-1.50; $P<0.05)$. Medications most commonly used by CD patients were "tranquillizers, relaxants, and sleeping pills" (consumed by $51.6 \%$ of patients), closely followed by "drugs for pain" (47.4\%), and $38.6 \%$ took medication described as "antidepressants/stimulants" (Figure 4).

\section{Discussion}

This is the first study conducted in Spain on HRQoL and use of health care resources among people diagnosed with $\mathrm{CD}$ that uses a primary data source representing the Spanish population. The results indicate that the impact of CD on patients' 
quality of life and on the limitations they face in everyday life is greater than the impact of OCCs included in the SNHS.

The analysis of the self-perception of each of the EQ5D-5L dimensions (mobility, self-care, daily activities, pain/ discomfort, anxiety/depression) shows that people diagnosed with CD report greater problems than people with OCCs in all the dimensions. Given that $67.6 \%$ of people with depression reported they have also been diagnosed with "chronic anxiety", it is not surprising that the anxiety/depression dimension is the most affected of the five dimensions. The mean utility level of persons with depression was 0.74 in our analysis, which is similar to the result of Saarni et al, ${ }^{11}$ where the utility level was determined for people diagnosed with "any depressive disorder" in Finland (mean utility $=0.73$ ), but higher than that of Fernández et al, ${ }^{19}$ one of the few Spanish studies to estimate utility levels of persons with depressive disorders (mean utility for dysthymia $=0.60$; mean utility for MDD $=0.53$ ). A comparison with the results of Fernández et al should be made with caution. Their study used the Short Form Health Survey (SF-6D) questionnaire, which has been shown to yield lower utility scores than the EQ-5D-5L in chronic conditions, ${ }^{31-33}$ is representative of the Catalonian population only, included people aged 18 years and above (we included people aged 18-64 years), and differentiated between disorder types, while our sample included all types of depression.

The average utility score of people diagnosed with $\mathrm{CD}$ was significantly lower than that of the population with OCCs. Our results indicate that after controlling for age, sex, and total number of comorbidities, a diagnosis of $\mathrm{CD}$ in persons aged between 18 and 64 years decreases utility by 0.09 when compared to OCCs. In the UK, Roberts et $\mathrm{al}^{10}$ found that depression resulted in a decrease of 0.16 in utility scores, and Sabes-Figuera et $\mathrm{al}^{18}$ found that depression and anxiety together reduced utility scores by 0.17 , but our results were not comparable with these studies. First, both studies used the EQ-5D-3L questionnaire, which has a lower sensitivity than the EQ-5D-5L, ${ }^{29}$ and second, both studies calculated utility decrements relative to the general population, which included persons with full health. Our comparison to people diagnosed with OCCs is likely to explain the lower utility difference found in our analysis.

QALYs can be obtained by multiplying utility values by the duration of the disease and, as with utility, their values range from death (0.0 QALY) to a year with perfect health (1.0 QALY). The SNHS does not record the person's age at which chronic conditions started, impeding, therefore, to know the length of time that the individual has been living with the disease. However, if we assume that people have been living with the utility level that they report for at least the past year, then in the past year, after controlling for number of comorbidities, age, and sex, each person with CD had 0.09 QALYs less on average than a person diagnosed with chronic conditions different to CD. If we extrapolate the prevalence that we found for $\mathrm{CD}$ in people aged between 18 and 64 years (6.1\%) to the Spanish population for the same age group according to the Spanish National Statistics Institute 2014 census $(38,722,159$ people), then 162,464 QALYs are lost each year in Spain as a result of $\mathrm{CD}$ alone in this age group, with respect to people diagnosed with OCCs. This shows the number of QALYs that would be gained by the Spanish population if the self-perceived quality of life of $\mathrm{CD}$ patients were improved to match the level of people diagnosed with the OCCs included in the SNHS.

The use of health care resources was higher among people with $\mathrm{CD}$ than among people who suffer from OCCs, in terms of number of visits to primary and secondary care physicians (however, the percentage of patients who visited primary and secondary care did not statistically differ between both groups), emergency services, hospital admissions, and hospital length of stay, as well as total consumption of prescribed medications. Only $38.6 \%$ of people diagnosed with $\mathrm{CD}$ reported taking antidepressants/stimulants. It should be noticed that the heterogeneity of our sample impeded differentiating between types and severity level of depression. People with less severe symptomatology may have reported a lower drug uptake than those with severe conditions because they did not need or want to be medicated. However, our finding is in line with the study of García-Campayo et al who found that $31 \%$ of patients diagnosed with MDD in the Spanish primary care setting were using antidepressants. ${ }^{21}$ Several studies have demonstrated that treatment with antidepressants significantly increases the HRQoL and decreases the symptoms of people with depressive disorders, which might in turn result in a possible reduction in the use of health care resources. ${ }^{34-41}$ However, the administration of psychotropic drugs depends on the patient characteristics and the disease severity. Since the SNHS does not allow distinguishing between different clinical categories of depression, our results merely shed light on the overall proportion of patients undergoing treatment for all types of depression in Spain.

"Chronic anxiety" was found to be the most prevalent comorbidity associated with $\mathrm{CD}$, with $67.7 \%$ of people with CD reporting suffering from "chronic anxiety". This figure coincides with the results of previous studies in which $50 \%-90 \%$ of patients with a depressive disorder developed symptoms of anxiety at some time. ${ }^{42}$ In Spain, $96.9 \%$ of patients diagnosed with generalized anxiety disorder have an associated disease such as chronic pain, sleep disorders, digestive disorders, cardiovascular diseases, diabetes, nonspecific 
psychiatric diseases, asthma, and others. ${ }^{8,43,44}$ Due to these comorbidities, patients diagnosed with generalized anxiety disorder are frequent users of heath care resources (medical visits, drugs, and hospital admissions), which entails more health care spending than for the general population. ${ }^{45}$ The fact that most patients with depression are also diagnosed with anxiety, when both pathologies have a high proportion of comorbidities that require medical care, could be one of the reasons these patients make greater use of health care resources than people who have been diagnosed with OCCs.

Depression has been associated with higher utilization of health care resources, higher health care costs, and with significant productivity losses. ${ }^{9,21,22}$ Salvador-Carulla et al found that in Catalonia, $78 \%$ of the total annual cost of depression corresponded to productivity losses in persons aged 18-64 years. ${ }^{22}$ Due to lack of data in the survey, we did not estimate health care costs and productivity losses in our study, and inferences regarding the magnitude of these costs cannot be made based solely on our results. Further research is required to calculate the economic impact of $\mathrm{CD}$ in Spain. This information, together with the calculation of QALYs lost due to this disease, would help to define health care budget spending priorities, to plan public health measures, and to evaluate the cost-effectiveness of future health policies for the prevention and treatment of depression.

Our findings are not free from limitations. First, the diagnosis reported by the people who took part in the SNHS 2011-2012 is not based on objective measurements of the presence of the disease but on self-reporting. Previous studies have shown that a large number of cases of depression remain undiagnosed for various reasons: 1) the somatic symptoms of the patients (insomnia, headache, fatigue, weight loss, etc) might be attributed to other physical diseases rather than to a possible mental disorder; 2) primary care physicians sometimes have difficulty in detecting psychiatric disorders; and 3) it can be difficult to distinguish between depression and anxiety when the patient develops both disorders at the same time, and people who have been diagnosed with an anxiety disorder (covered by the term "chronic anxiety" in the survey) could, in fact, be suffering from depression. ${ }^{26,46,47}$ Possible underdiagnosis implies that the rate of prevalence of depression in our findings may be underestimated. In this case, we could be underestimating the true magnitude of total QALYs lost by society as well as the use of health care resources among people with CD. Second, as was noted before, the SNHS 2011-2012 does not allow interviewees to distinguish between different clinical categories of diagnosed depression (MDD, dysthymia, or other), which impedes comparing our results with those of other studies that do distinguish between different depression diagnoses. To this date, data from the SNHS are the only data that allow describing both the health status and the use of resources among people with depression at the national level in Spain. Future SNHSs ought to consider including different depressive disorders among the chronic conditions included so far, to allow research questions to focus on one or more types of depression. Finally, as the SNHS is a cross-sectional survey, the data collected with respect to quality of life are only representative of a specific moment in time. The calculation of QALYs lost each year by people with $\mathrm{CD}$ assumes that their self-reported quality of life remains constant over the whole year, but in fact it may vary.

\section{Conclusion}

Despite the limitations of the study, our findings indicate that people diagnosed with depression have a significantly lower quality of life than those diagnosed with OCCs. The results also show that $\mathrm{CD}$ is associated with a higher number of visits to primary and secondary health care services, longer hospital length of stay, higher use of emergency services, and higher drug consumption than OCCs. Our results emphasize the need for actively promoting health care and comprehensive treatment measures for $\mathrm{CD}$ that aim to improve the quality of life of people diagnosed with this disease. This could also lead to a decrease in the use of emergency services, hospital length of stay, and overall drug consumption, as long as this health care use was caused by depression or its consequences, and assuming that the use of these resources was associated with the self-perceived quality of life of people diagnosed with depression.

\section{Author contributions}

All authors contributed toward data analysis, drafting and revising the paper and agree to be accountable for all aspects of the work.

\section{Acknowledgment}

The study was funded by Lundbeck.

\section{Disclosure}

The authors report no conflicts of interest in this work.

\section{References}

1. World Health Organisation. Depression. WHO (2015). Available from http:/www.who.int/mediacentre/factsheets/fs369/es/. Accessed February $10,2016$.

2. Sadock BJ, Sadock, VA, Kaplan HI. Kaplan \& Sadock's comprehensive textbook of psychiatry. Wolters Kluwer Health/Lippincott Williams \& Wilkins; 2009

3. Center for on-line Biomedic Research in Mental Health (Spain) Mental Health Strategic Plan for 2014-2016. 2013. Available from http://www.ciberisciii.es/ficheros/SAM/1_Plan\%20Estrategico\%20 CIBERSAM_2014_vf_161213.pdf. Accessed August 19, 2016. 
4. Haro JM, Palacín C, Vilagut G, et al. Prevalencia de los trastornos mentales y factores asociados: resultados del estudio ESEMeD-España [Prevalence of mental disorders and associated factors: results from the ESEMeD-Spain study]. Med Clínica. 2006;126:445-451. Spanish.

5. Reneses B, Garrido S, Navalón A, et al. Psychiatric morbidity and predisposing factors in a primary care population in Madrid. Int $J$ Soc Psychiatry. 2015;61(3):275-286.

6. Alonso J, Codony M, Kovess V, et al. Population level of unmet need for mental healthcare in Europe. Br J Psychiatry J Ment Sci. 2007;190(4): 299-306.

7. de Waal MW, Arnold IA, Spinhoven P, Eekhof JA, Assendelft WJ, van Hemert AM. The role of comorbidity in the detection of psychiatric disorders with checklists for mental and physical symptoms in primary care. Soc Psychiatry Psychiatr Epidemiol. 2009;44(1):78-85.

8. García-Campayo J, Caballero F, Perez M, López V. Prevalence and clinical features of newly diagnosed generalized anxiety disorder patients in Spanish primary care settings: the GADAP study. Actas Esp Psiquiatr. 2012;40(3):105-113.

9. Zhu B, Zhao Z, Ye W, Marciniak MD, Swindle R. The cost of comorbid depression and pain for individuals diagnosed with generalized anxiety disorder. J Nerv Ment Dis. 2009;197(2):136-139.

10. Roberts J, Lenton P, Keetharuth AD, Brazier J. Quality of life impact of mental health conditions in England: results from the adult psychiatric morbidity surveys. Health Qual Life Outcomes. 2014;12:6.

11. Saarni SI, Suvisaari J, Sintonen H, et al. Impact of psychiatric disorders on health-related quality of life: general population survey. $\mathrm{Br} J$ Psychiatry. 2007;190:326-332.

12. Sapin C, Fantino B, Nowicki M-L, Kind P. Usefulness of EQ-5D in assessing health status in primary care patients with major depressive disorder. Health Qual Life Outcomes. 2004;2:20.

13. Pirkola S, Saarni S, Suvisaari J, et al. General health and qualityof-life measures in active, recent, and comorbid mental disorders: a population-based health 2000 study. Compr Psychiatry. 2009;50(2): 108-114.

14. Burström K, Johannesson M, Diderichsen F. Health-related quality of life by disease and socio-economic group in the general population in Sweden. Health Policy. 2001;55(1):51-69.

15. Günther $\mathrm{OH}$, Roick C, Angermeyer MC, König H-H. The responsiveness of EQ-5D utility scores in patients with depression: a comparison with instruments measuring quality of life, psychopathology and social functioning. J Affect Disord. 2008;105(1-3):81-91.

16. Ishak WW, Balayan $\mathrm{K}$, Bresee $\mathrm{C}$, et al. A descriptive analysis of quality of life using patient-reported measures in major depressive disorder in a naturalistic outpatient setting. Qual Life Res. 2013;22(3):585-596.

17. Rapaport MH, Clary C, Fayyad R, Endicott J. Quality-of-life impairment in depressive and anxiety disorders. Am J Psychiatry. 2005;162(6): 1171-1178.

18. Sabes-Figuera R, Knapp M, Bendeck M, Mompart-Penina A, SalvadorCarulla L. The local burden of emotional disorders. An analysis based on a large health survey in Catalonia (Spain). Gac Sanit. 2012;26(1):24-29.

19. Fernández A, Saameño JAB, Pinto-Meza A, et al. Burden of chronic physical conditions and mental disorders in primary care. Br JPsychiatry J Ment Sci. 2010;196(4):302-309.

20. Luber MP, Meyers BS, Williams-Russo PG, et al. Depression and service utilization in elderly primary care patients. Am J Geriatr Psychiatry. 2001;9(2):169-176.

21. García-Campayo J, Ayuso-Mateos JL, Caballero L, et al. Relationship of somatic symptoms with depression severity, quality of life, and health resources utilization in patients with major depressive disorder seeking primary health care in Spain. Prim Care Companion J Clin Psychiatry. 2008;10(5):355-362.

22. Salvador-Carulla L, Bendeck M, Fernández A, et al. Costs of depression in Catalonia (Spain). J Affect Disord. 2011;132(1-2):130-138.

23. EU Council Conclusions Chronic Diseases. 2010. Available from: http:// www.idf.org/sites/default/files/Council_conclusions_7\%20Dec\%20 2010_Chronic\%20Disease.pdf. Accessed June 15, 2016.
24. Spanish Ministry of Health. Estrategia para el abordaje de la cronicidad: El paso necesario [Strategical Plan to Address Chronicity]. 2013. Available from: http://www.msssi.gob.es/organizacion/sns/planCalidadSNS/ pdf/ESTRATEGIA_ABORDAJE_CRONICIDAD.pdf. Accessed June 15, 2016. Spanish.

25. Spanish Ministry of Health. Plan Estratégico de Calidad del Sistema Nacional de Salud. Balance de actividades y acciones previstas 2011-2015 [Strategical Quality Plan for the National Health Service. Activities' balance and foreseen actions 2011-2015]. 2015. Available from: http://www.msssi.gob.es/organizacion/sns/planCalidadSNS/docs/ InformePlanCalidad_ESP.pdf. Accessed June 15, 2016. Spanish.

26. Baca Baldomero E, Sáiz Ruiz J, Porras Chavarino A. The detection of mental disorders by physicians who are not psychiatrists: usefulness of the PRIME-MD questionnaire. Med Clínica. 2001;116: 504-509.

27. Durán Heras MA. Los costes invisibles de las enfermedades mentales [The invisible costs of mental illnesses]. Goze. 2000;3:10. Spanish.

28. Instituto Nacional de Estadística. Encuesta Nacional de Salud 20112012 [National Statistics Institute (Spain). National Health Survey 2011-2012]. Available from: http:/www.msssi.gob.es/estadEstudios/ estadisticas/encuestaNacional/encuesta2011.htm. Accessed June 15, 2016. Spanish.

29. Herdman M, Gudex C, Lloyd A, et al. Development and preliminary testing of the new five-level version of EQ-5D (EQ-5D-5L). Qual Life Res. 2011;20(10):1727-1736.

30. Ramos-Goñi JM, Pinto-Prades JL, Oppe M, et al. Valuation and modeling of EQ-5D-5L health states using a hybrid approach. Med Care. Epub 2014 Dec 17

31. McCrone P, Patel A, Knapp M, et al. A comparison of SF-6D and EQ-5D utility scores in a study of patients with schizophrenia. J Ment Health Policy Econ. 2009;12(1):27-31.

32. Chen J, Wong CKH, McGhee SM, Pang PKP, Yu W-C. A comparison between the EQ-5D and the SF-6D in patients with chronic obstructive pulmonary disease (COPD). PLoS One. 2014;9(11):e112389.

33. van Stel HF, Buskens E. Comparison of the SF-6D and the EQ-5D in patients with coronary heart disease. Health Qual Life Outcomes. 2006;4:20.

34. IsHak WW, Mirocha J, James D, et al. Quality of life in major depressive disorder before/after multiple steps of treatment and one-year follow-up. Acta Psychiatr Scand. 2015;131(1):51-60.

35. Trinadade E, Menon D, Topfer L-A, Coloma C. Adverse effects associated with selective serotonin reuptake inhibitors and tricyclic antidepressants: a meta-analysis. Can Med Assoc J. 1998;159:1245-1252.

36. Goldsmith SK, Pellmar TC, Kleinman AM, Bunney WE. Reducing Suicide: A National Imperative. Vol xv. Washington, DC: National Academies Press; 2002.

37. Mallick R, Chen J, Entsuah AR, Schatzberg AF. Depression-free days as a summary measure of the temporal pattern of response and remission in the treatment of major depression: a comparison of venlafaxine, selective serotonin reuptake inhibitors, and placebo. J Clin Psychiatry. 2003;64:321-330

38. Ryan NE. Medication treatment for depression in children and adolescents. CNS Spectrums. 2003;8(4):283-287.

39. Green B. Focus on paroxetine. Curr Med Res Opin. 2003;19:13-21.

40. Vaswani M, Linda FK, Ramesh S. Role of selective serotonin reuptake inhibitors in psychiatric disorders: a comprehensive review. Prog Neuropsychopharmacol Biol Psychiatry. 2003;27:85-102.

41. von Wolff A, Hölzel LP, Westphal A, Härter M, Kriston L. Selective serotonin reuptake inhibitors and tricyclic antidepressants in the acute treatment of chronic depression and dysthymia: a systematic review and meta-analysis. J Affect Disord. 2013;144:7-15.

42. Consejo General de Colegios Oficiales de Farmacéuticos. Trastornos del estado de ánimo: Depresión y Ansiedad. Guía Farmacoterapéutica [Mood disorders: Depression and Anxiety. Pharmacotherapeutic Guide]. 2009. Available from: https://botplusweb.portalfarma.com/ Documentos/2009/2/11/37502.pdf. Accessed August 26, 2016. Spanish. 
43. Romera I, Fernandez-Perez S, Montejo AL, et al. Generalized anxiety disorder, with or without co-morbid major depressive disorder, in primary care: prevalence of painful somatic symptoms, functioning and health status. J Affect Disord. 2010;127:160-168.

44. Álvarez E, Carrasco JL, Olivares JM, et al. Broadening of generalized anxiety disorders definition does not affect the response to psychiatric care: findings from the observational ADAN study. Clin Pract Epidemiol Ment Health. 2012;8:158.

45. Andlin-Sobocki P, Wittchen H-U. Cost of anxiety disorders in Europe. Eur J Neurol. 2005;12:39-44.
46. Postigo JML, Bravo BN, Delgado MP, Salguero JM, Wood CM, Vindel AC. Evaluación e intervención de los problemas de Ansiedad y Depresión en Atención Primaria: Un Problema sin resolver [Assessment and intervention of Anxiety and Depression disorders in Primary Care: An unsolved problem]. Rev Clínica Med Fam. 2012;5:37-45. Spanish.

47. Means-Christensen AJ, Sherbourne CD, Roy-Byrne PP, et al. In search of mixed anxiety-depressive disorder: a primary care study. Depress Anxiety. 2006;23:183-189.
Patient Related Outcome Measures

\section{Publish your work in this journal}

Patient Related Outcome Measures is an international, peer-reviewed, open access journal focusing on treatment outcomes specifically relevant to patients. All aspects of patient care are addressed within the journal and practitioners from all disciplines are invited to submit their work as well as healthcare researchers and patient support groups.
The journal is included in PubMed. The manuscript management system is completely online and includes a very quick and fair peer-review system. Visit http://www.dovepress.com/testimonials.php to read real quotes from published authors. 